\title{
STUDIES ON CARBOHYDRATE METABOLISM IN PATIENTS WITH NEOPLASTIC DISEASE. II. REPONSE TO INSULIN ADMINISTRATION * $†$
}

\author{
By JONATHAN S. BISHOP $\ddagger$ AND PAUL A. MARKS \\ (From the Department of Medicine, College of Physicians and Surgeons, Columbia University, \\ and the Medical Service of the Francis Delafield Hospital and the Presbyterian \\ Hospital, New York City, N. Y.)
}

(Submitted for publication November 20, 1958; accepted December 11, 1958)

A decrease in glucose tolerance, as indicated by a slower rate of disappearance of blood glucose following intravenous glucose administration, has been observed in patients with neoplastic disease (2). The group studied included subjects with chronic diffuse lymphomas and leukemias as well as clinically localized carcinomas who were carefully selected to exclude various other factors known to influence carbohydrate utilization. In view of the fact that the altered glucose metabolism was associated with localized carcinoma, it appeared likely that it reflected a defect in the metabolism of the host. The mechanism of this defect is unknown.

In view of suggestions $(3,4)$ that endogenous insulin secretion determines the rate of blood glucose disappearance, the decreased glucose tolerance might reflect either diminished secretion of, or a diminished responsiveness to, endogenous insulin. On the assumption that sensitivity to exogenously administered insulin reflects responsiveness to the endogenously secreted hormone, insulin response tests have been performed in patients with neoplastic disease. This has been done employing a three hour test procedure which permitted the determination of the rate constant of the decline in blood glucose concentration, first, following the intravenous administration of glucose sufficient to cause hyperglycemia, and second, following the intravenous administration of insulin. It was found that patients with neoplastic disease, compared to control subjects, had an impaired re-

* A portion of the present data was presented before the American Association for Cancer Research, April, 1957, and appears in abstract form (1).

† This work was supported in part by Grant C2332 of the National Cancer Institute.

$\ddagger$ Clinical Fellow of the American Cancer Society. Present address: Biology Department, Brookhaven National Laboratory, Upton, N. Y. sponse to insulin as well as a decreased glucose tolerance.

\section{METHODS}

Subjects studied. The control group consisted of 16 individuals without neoplastic disease, eight males and eight females, ranging in age from 36 to 61 years. The patients with neoplastic disease included 24 individuals, 11 males and 13 females, ranging in age from 33 to 71 years. There were no significant differences between the control and the patient groups with respect to age or body weight. The diagnoses of these subjects are indicated in Tables I and II. Criteria (2) were used in selection of the subjects for this study which insured, as far as was possible on a clinical basis, that tests were performed only on persons in whom various factors known to impair carbohydrate metabolism could be excluded.

Procedures. All subjects were placed on a daily diet containing at least $225 \mathrm{Gm}$. of carbohydrate and 2,400 calories for more than one week prior to study. Each subject, following an overnight fast, rested in an airconditioned room for one-half hour prior to and during the test. An indwelling, Cournand-type needle was placed in an antecubital vein. After two fasting blood samples had been obtained over a period of 20 to 30 minutes, approximately $25 \mathrm{Gm}$. of glucose (as a 30 per cent solution in distilled water) was injected into another vein over a four minute period. Following the completion of the glucose injection venous blood samples were withdrawn without stasis into heparinized syringes at eight minute intervals for 64 minutes. At approximately 75 minutes following the glucose injection, another sample of blood was obtained and a standard dose of glucagonfree insulin 1 ( 0.1 unit per $\mathrm{Kg}$. body weight) was administered intravenously through the indwelling needle. Seven venous blood samples were obtained at three minute intervals between seven and 25 minutes following the insulin injection. Then the test was terminated by the intravenous administration of $30 \mathrm{ml}$. of a 30 per cent glucose solution and the oral administration of sweetened orange juice. The development of hypoglycemic symptoms necessitated earlier termination of the procedure in only two subjects.

1 Glucagon-free insulin was kindly supplied by The Eli Lilly Co., Indianapolis, Ind. 
TABLE I

Response to intravenous administration of glucose followed by insulin in control subjects

\begin{tabular}{|c|c|c|c|c|c|}
\hline \multirow[b]{2}{*}{$\begin{array}{l}\text { Subject } \\
\text { number* }\end{array}$} & \multicolumn{2}{|c|}{ Blood glucose concentration } & \multicolumn{3}{|c|}{$\begin{array}{l}\text { Rate constants of decline in blood } \\
\text { glucose concentration } \delta\end{array}$} \\
\hline & Fasting $†$ & $\begin{array}{l}\text { Before } \\
\text { insulin } \ddagger\end{array}$ & $\mathbf{k q}$ & $\mathbf{k I}$ & $\mathbf{k I} / \mathbf{k a}$ \\
\hline $\begin{array}{r}1 \\
2 \\
3 \\
4 \\
5 \\
6 \\
7 \\
8 \\
9 \\
10 \\
11 \\
12 \\
13 \\
14 \\
15 \\
16\end{array}$ & $\begin{array}{l}m g . \% \\
85-88 \\
78-80 \\
83-81 \\
81-72 \\
92-88 \\
76-77 \\
83-85 \\
88-86 \\
80-82 \\
86-90 \\
87-88 \\
83-90 \\
78-82 \\
82-85 \\
83-86 \\
81-85\end{array}$ & $\begin{array}{c}\text { mg. } \% \\
73 \\
76 \\
64 \\
104 \\
131 \\
104 \\
84 \\
88 \\
114 \\
104 \\
100 \\
106 \\
91 \\
97 \\
95 \\
94\end{array}$ & $\begin{array}{c}\text { \%/min. } \\
1.31 \\
1.58 \\
1.88 \\
1.59 \\
1.61 \\
1.26 \\
2.15 \\
1.92 \\
1.87 \\
1.84 \\
1.69 \\
2.21 \\
1.98 \\
1.82 \\
1.89 \\
1.60\end{array}$ & $\begin{array}{r}\% / \min . \\
4.62 \\
9.90 \\
6.30 \\
6.90 \\
4.78 \\
5.92 \\
10.30 \\
6.30 \\
7.42 \\
8.00 \\
6.12 \\
9.30 \\
7.04 \\
6.42 \\
6.00 \\
5.00\end{array}$ & $\begin{array}{l}3.53 \\
6.27 \\
3.35 \\
4.34 \\
2.97 \\
4.70 \\
4.79 \\
3.28 \\
3.97 \\
4.35 \\
3.62 \\
4.21 \\
3.56 \\
3.53 \\
3.17 \\
3.13\end{array}$ \\
\hline $\begin{array}{l}\text { Average } \\
\text { S. D. }\end{array}$ & $\begin{array}{r}83 \\
4\end{array}$ & $\begin{array}{l}95 \\
16\end{array}$ & $\begin{array}{l}1.76 \\
0.26\end{array}$ & $\begin{array}{l}6.90 \\
1.86\end{array}$ & $\begin{array}{l}3.92 \\
0.82\end{array}$ \\
\hline
\end{tabular}

* Diagnoses: Subjects 1 and 3, benign breast adenoma; Subject 2, bronchopneumonia, convalescent; Subject 10, cervical erosion; Subjects 13 and 14, tuberculoma of the lung; Subjects 4-9, 11, 12, 15, 16, normal volunteers.

$t$ Two fasting blood sugar determinations were performed approximately 20 minutes apart.

¥ This blood sugar determination was performed approximately 75 minutes following glucose administration and immediately prior to insulin injection.

$\$ k_{G}$ represents the rate constant following glucose administration; $k_{I}$ represents the rate constant following insulin administration.

Whole blood glucose concentrations were determined in duplicate by the Nelson modification of the Somogyi method $(5,6)$.

Analysis of the responses to glucose and to insulin administration. The responses to glucose and to insulin administration were analyzed by graphing the logarithm of the total blood glucose concentration against time (7). It was observed that the biood glucose concentration decreased at an exponential rate during the mid-portion of the period following both glucose and insulin administration. This linear function persisted for at least 40 minutes after glucose administration and at least 12 minutes after insulin administration. It is assumed that during this period of exponential decline of the total blood glucose concentration the slope of the plotted curve provides an index of the response to either glucose or insulin administration. This index may be expressed as the rate constant for the assumed first-order reaction according to the equation:

$$
\mathrm{k}_{\mathrm{G}} \text { or } \mathrm{k}_{\mathrm{I}}=\frac{\log _{\mathrm{e}} 2}{\mathrm{t}_{\mathrm{i}}}
$$

where $k_{G}$ and $k_{I}$ are the fractional rate constants of disappearance of blood glucose following glucose or following insulin administration, respectively, and $t_{1 / 2}$ is the time in minutes for the total blood glucose concentration to decline 50 per cent from any point after glucose or after insulin administration, respectively. An example of this graphic analysis is presented in Figure 1.
It has been previously demonstrated (2) that this empirical method of analysis of intravenous glucose tolerance curves provides good reproducibility in a given subject, and good discrimination between the control and neoplastic groups.

\section{RESULTS}

The data obtained from the tests of the response to glucose and to insulin administration in 16 control subjects and 24 patients with neoplastic disease are summarized in Tables I and II. The rate constant for the decline in blood glucose concentration after insulin administration $\left(\mathrm{k}_{\mathrm{I}}\right)$ for the control group was $6.90 \pm 1.86$ per cent per minute $^{2}$ compared to $3.99 \pm 1.30$ per cent per minute in the patient group. The similar rate constant after glucose administration $\left(\mathrm{k}_{\mathrm{G}}\right)$ was $1.76 \pm 0.25$ per cent per minute for the control group and $1.18 \pm 0.37$ per cent per minute for the patient group. The differences between the means of both $\mathrm{k}_{\mathrm{I}}$ and $\mathrm{k}_{\mathrm{G}}$ were statistically significant, $\mathbf{5 . 5}$ and 5.9 times the standard error of the difference, respectively. The values for $k_{G}$ in the control and patient groups are in agreement with previous

\footnotetext{
2 Average values are given with one standard deviation.
} 
studies of a larger number of subjects (2). The ratio of $\mathrm{k}_{\mathrm{I}} / \mathrm{k}_{\mathrm{G}}$ for the control and the patient groups were $3.92 \pm 0.82$ and $3.46 \pm 0.91$, respectively. These ratios are not significantly different.

The fasting blood glucose concentration averaged $83 \pm 4 \mathrm{mg}$. per cent in the control group and $85 \pm 10 \mathrm{mg}$. per cent in the patient group. The difference between these means is not statistically significant. The blood glucose concentration prior to the administration of insulin did not differ significantly in the two groups $(95 \pm 16 \mathrm{mg}$. per cent and $109 \pm 25 \mathrm{mg}$. per cent in the control and patient groups, respectively). Nevertheless there was a tendency for the glucose concentration to be higher in the patient group than in the control at the time of insulin administration. Accordingly, the effect of varying concentrations of blood glucose at the time of insulin administra- tion upon $k_{I}$ was studied in three patients with neoplastic disease and in three control subjects (Table III). In these six subjects, $\mathrm{k}_{\mathrm{I}}$ differed slightly, if at all, on repeat studies, despite differences in the pre-insulin administration blood glucose concentrations of 25 to $65 \mathrm{mg}$. per cent.

\section{DISCUSSION}

A decreased sensitivity to insulin, as indicated by a slower rate of decline in blood glucose concentration following the intravenous administration of this hormone, was observed in patients with neoplastic disease. These subjects also demonstrated impaired glucose tolerance, as previously described $(2,8-13)$.

In terms of the rate of disappearance of blood glucose, the patients with neoplastic disease ex-

TABLE II

Response to intravenous administration of glucose followed by insulin in patients with neoplastic disease

\begin{tabular}{|c|c|c|c|c|c|}
\hline \multirow[b]{2}{*}{$\begin{array}{l}\text { Subject } \\
\text { number* }\end{array}$} & \multicolumn{2}{|c|}{ Blood glucose concentration } & \multicolumn{3}{|c|}{$\begin{array}{l}\text { Rate constants of decline in blood } \\
\text { glucose concentration } \S\end{array}$} \\
\hline & Fasting $\dagger$ & $\begin{array}{l}\text { Before } \\
\text { insulin } \ddagger\end{array}$ & $\mathbf{k a}$ & kI & $\mathrm{kI} / \mathrm{ka}$ \\
\hline $\begin{array}{l}17 \\
18 \\
19 \\
20 \\
21 \\
22 \\
23 \\
24 \\
25 \\
26 \\
27 \\
28 \\
29 \\
30 \\
31 \\
32 \\
33 \\
34 \\
35 \\
36 \\
37 \\
38 \\
39 \\
40\end{array}$ & $\begin{array}{c}m g . \% \\
98-93 \\
84-81 \\
80-81 \\
80-84 \\
88-87 \\
119-115 \\
80-85 \\
98-94 \\
89-87 \\
89-84 \\
86-84 \\
85-88 \\
82-86 \\
78-74 \\
82-73 \\
75-78 \\
75-74 \\
87-89 \\
91-91 \\
88-93 \\
54-63 \\
77-75 \\
87-89 \\
84-84\end{array}$ & $\begin{array}{c}\text { mg. } \% \\
150 \\
106 \\
128 \\
93 \\
89 \\
178 \\
116 \\
108 \\
84 \\
96 \\
147 \\
100 \\
90 \\
80 \\
80 \\
94 \\
84 \\
114 \\
92 \\
108 \\
127 \\
90 \\
116 \\
150\end{array}$ & $\begin{array}{c}\text { \%/min. } \\
0.90 \\
1.33 \\
1.17 \\
1.17 \\
1.24 \\
0.94 \\
1.25 \\
1.12 \\
1.80 \\
1.21 \\
1.05 \\
1.21 \\
0.90 \\
2.36 \\
0.93 \\
1.82 \\
1.41 \\
0.75 \\
1.10 \\
1.07 \\
0.90 \\
1.16 \\
1.05 \\
0.53\end{array}$ & $\begin{array}{l}\% / \min . \\
3.96 \\
5.90 \\
4.34 \\
3.07 \\
3.98 \\
2.47 \\
4.60 \\
3.66 \\
4.84 \\
2.95 \\
4.77 \\
2.89 \\
2.57 \\
7.80 \\
2.28 \\
4.62 \\
4.47 \\
2.16 \\
6.00 \\
3.19 \\
3.85 \\
4.46 \\
3.85 \\
2.99\end{array}$ & $\begin{array}{l}4.40 \\
4.44 \\
3.71 \\
2.62 \\
3.21 \\
2.63 \\
3.68 \\
3.27 \\
2.69 \\
2.44 \\
4.54 \\
2.39 \\
2.86 \\
3.31 \\
2.45 \\
2.54 \\
3.17 \\
2.88 \\
5.45 \\
2.98 \\
4.28 \\
3.84 \\
3.67 \\
5.64\end{array}$ \\
\hline $\begin{array}{l}\text { Average } \\
\text { S. D. }\end{array}$ & $\begin{array}{l}85 \\
10\end{array}$ & $\begin{array}{r}109 \\
25\end{array}$ & $\begin{array}{l}1.18 \\
0.37\end{array}$ & $\begin{array}{l}3.99 \\
1.30\end{array}$ & $\begin{array}{l}3.46 \\
0.91\end{array}$ \\
\hline
\end{tabular}

* Diagnoses: Cases 17-21, carcinoma of the cervix, clinical stage I or II ; Cases 22-24, carcinoma of the breast Cases 25-29, Hodgkins disease; Cases 30 and 31, reticulum cell sarcoma; Cases 32-36, lymphosarcoma; Case 37, chronic lymphatic leukemia; Cases 38 and 39, chronic myelogenous leukemia; Case 40, giant follicular lymphosarcoma.

$\dagger$ Two fasting blood sugar determinations were performed approximately 20 minutes apart.

This blood sugar determination was performed approximately 75 minutes following glucose administration and immediately prior to insulin injection.

$\$ \mathrm{k}_{\mathrm{G}}$ represents the rate constant following glucose administration; $\mathrm{k}_{\mathrm{I}}$ represents the rate constant following insulin administration. 


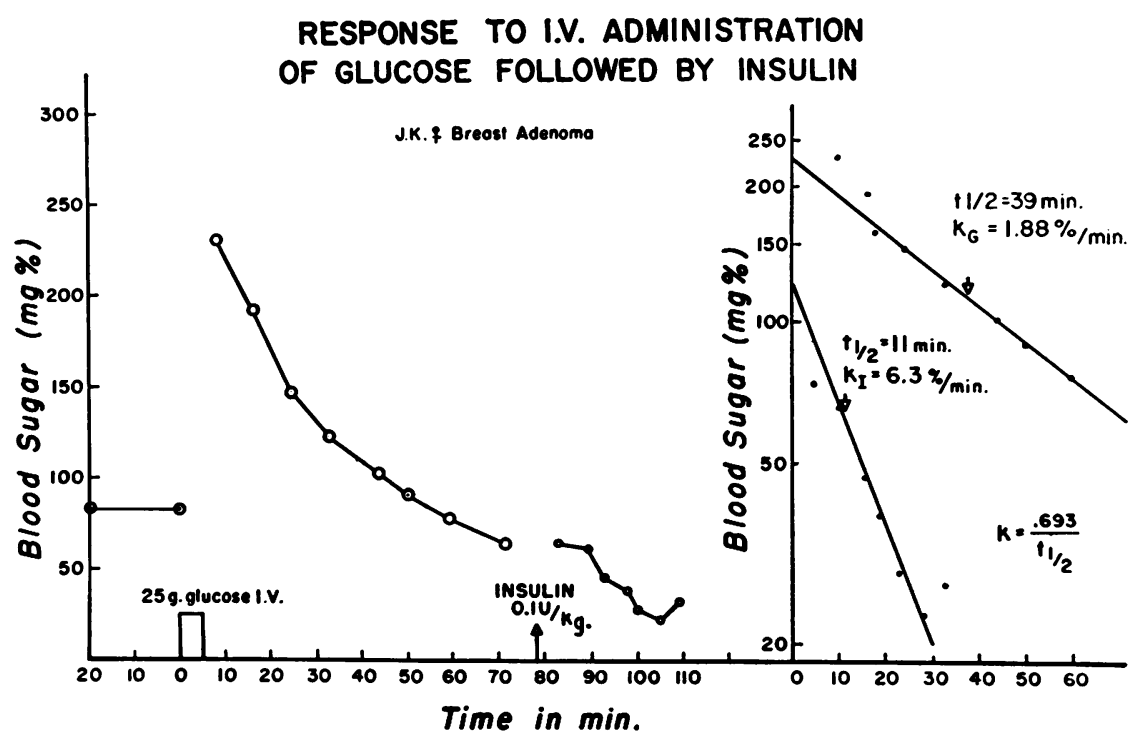

Fig. 1. Response to I.V. Administration of Glucose Followed by Insulin

The left-hand portion of this figure presents the blood glucose concentration data after intravenous administration of glucose followed by insulin in control Subject J.K. The right-hand portion of this figure presents the graphic analysis of these data to obtain the rate constants of glucose disappearance following administration of glucose $\left(k_{G}\right)$ and insulin $\left(K_{I}\right)$. $T_{1 / 2}$ is the time in minutes for the total blood glucose concentration to decline 50 per cent from any point after glucose or insulin injection.

hibited the same relative degree of unresponsiveness to exogenous insulin as to intravenously administered glucose. This is indicated by the finding that the ratio of the rate constants, $\mathrm{k}_{\mathrm{I}} / \mathrm{k}_{\mathrm{G}}$, did not differ significantly in the patient and control groups. In view of the evidence that the rate of blood glucose disappearance during hyperglycemia may be determined by endogenous insulin secretion $(3,4)$, these observations are compatible with the concept that impaired glucose tolerance in patients with neoplastic disease may be a manifestation of a decreased responsiveness to endogenous insulin.

It is to be stressed that a decrease in reponsiveness to insulin is not specific. It has been described in a variety of disorders $(14,15)$, including diabetes mellitus, endocrine dysfunctions, hepatic disease and infectious diseases and in association with increasing age (16).

The present study indicates that decreased in-

TABLE III

The effect of different concentrations of blood glucose on the response to insulin administration

\begin{tabular}{|c|c|c|c|c|c|}
\hline \multirow[b]{2}{*}{$\begin{array}{c}\text { Subject } \\
\text { no. }\end{array}$} & \multicolumn{2}{|c|}{ Patients with neoplastic disease } & \multirow[b]{2}{*}{$\begin{array}{c}\text { Subject } \\
\text { no. }\end{array}$} & \multicolumn{2}{|c|}{ Control subjects } \\
\hline & $\begin{array}{l}\text { Blood glucose } \\
\text { concentration } \\
\text { before insulin* }\end{array}$ & $\begin{array}{c}\text { Rate } \\
\text { constant } \\
\mathbf{k}_{\mathbf{I}}\end{array}$ & & $\begin{array}{l}\text { Blood glucose } \\
\text { concentration } \\
\text { before insulin } \dagger\end{array}$ & $\begin{array}{c}\text { Rate } \\
\text { constant } \\
\text { kI }\end{array}$ \\
\hline 33 & $\begin{array}{c}m g . \% \\
84 \\
120\end{array}$ & $\begin{array}{l}\% / \min . \\
4.47 \\
4.50\end{array}$ & 4 & $\begin{array}{l}m g . \% \\
104 \\
159\end{array}$ & $\begin{array}{l}\% / \min . \\
6.90 \\
6.50\end{array}$ \\
\hline 37 & $\begin{array}{l}127 \\
151\end{array}$ & $\begin{array}{l}3.85 \\
3.70\end{array}$ & 10 & $\begin{array}{l}104 \\
131\end{array}$ & $\begin{array}{l}8.00 \\
8.54\end{array}$ \\
\hline 38 & $\begin{array}{r}90 \\
118\end{array}$ & $\begin{array}{l}4.46 \\
4.68\end{array}$ & 16 & $\begin{array}{r}94 \\
158\end{array}$ & $\begin{array}{l}5.00 \\
4.74\end{array}$ \\
\hline
\end{tabular}

* Insulin was administered to the patients 75 minutes following glucose administration.

$\dagger$ Insulin was administered to the control subjects $\mathbf{4 0}$ minutes following glucose administration. 
sulin responsiveness is a manifestation of the metabolic alterations associated with neoplasia in the human host, but provides no data which permit conclusions as to the mechanism of this alteration in hormonal control.

\section{SUM MARY}

1. A procedure for testing the response to intravenous glucose administration as well as the response to intravenous insulin administration has been employed which permits their comparison by means of the rate constant of the decline in blood glucose concentration. This procedure is performed in a given subject during a single three hour study.

2. An impaired response to insulin administration as well as the previously described impairment in glucose tolerance was observed in 24 patients with neoplastic disease, when compared with 16 control subjects.

\section{REFERENCES}

1. Marks, P. A., and Bishop, J. S. Glucose metabolism in subjects with neoplastic disease: Response to insulin and glucose tolerance follow-up studies. Proc. Amer. Ass. Cancer Res. 1957, 2, 228.

2. Marks, P. A., and Bishop, J. S. The glucose metabolism of patients with malignant disease and of normal subjects as studied by means of an intravenous glucose tolerance test. J. clin. Invest. 1957, 36, 254.

3. Pozza, G., Galansino, G., Hoffeld, H., and Foà, P. P. Stimulation of insulin output by monosaccharides and monosaccharide derivatives. Amer. J. Physiol. 1958, 192, 497.
4. Wall, J. S., Steele, R., de Bodo, R. C., and Altszuler, N. Effect of insulin on utilization and production of circulating glucose. Amer. J. Physiol. 1957, 189, 43.

5. Nelson, N. A photometric adaptation of the Somogyi method for determination of glucose. J. biol. Chem. 1944, 153, 375.

6. Somogyi, M. A new reagent for the determination of sugars. J. biol. Chem. 1945, 160, 61.

7. Conard, V., Franckson, J. R. M., Bastenie, P. A., and Kovacs, L. Etude critique du triangle d'hyperglycémie intraveineux chez l'homme normal et détermination d'un "coefficient d'assimilation glucidique." Arch. int. Pharmacodyn. 1953, 93, 277.

8. Rohdenburg, G. L., Bernhard, A., and Krehbiel, O. Sugar tolerance in cancer. J. Amer. med. Ass. 1919, 72, 1528.

9. Edwards, S. Blood sugar tolerance in cancer. J. Indiana med. Ass. 1919, 12, 296.

10. Friedenwald, J. R., and Grove, G. H. The bloodsugar tolerance test as an aid in the diagnosis of gastro-intestinal cancer. Amer. J. med. Sci. 1920, $160,313$.

11. Langston, W. Glucose tolerance test. J. Lab. clin. Med. 1922, 7, 293.

12. Andersen, P. E. Variations in the glucose tolerance test curves in patients with endometrial carcinoma. Acta radiol. (Stockh.) 1952, 37, 178.

13. Glicksman, A. S., Myers, W. P. L., and Rawson, R. W. Diabetes mellitus and carbohydrate metabolism in patients with cancer. Med. Clin. N. Amer. 1956, 40, 887.

14. Himsworth, H. P. The physiological activation of insulin. Clin. Sci. 1933, $1,1$.

15. de Bodo, R. C., and Altszuler, N. Insulin hypersensitivity and physiological insulin antagonists. Physiol. Rev. 1958, 38, 389.

16. Silverstone, F. A., Brandfonbrener, M., Shock, N. W., and Yiengst, M. J. Age differences in the intravenous glucose tolerance tests and the response to insulin. J. clin. Invest. 1957, 36, 504. 